J. Asiat. Soc. Bangladesh, Sci. 39(2): 247-257, December 2013

\title{
HIGH TEMPERATURE TREATMENT ON THE EGGS OF THE MOSQUITO, CULEX QUINQUEFASCIATUS SAY AND ITS EFFECTS ON THE SUBSEQUENT STAGES DEVELOPED THEREFROM
}

\author{
HUMAYUN REZA KHAN AND MD. MOSARRAF HOSSAIN \\ Department of Zoology, University of Dhaka, Dhaka 1000, Bangladesh
}

\begin{abstract}
The eggs of Culex quinquefasciatus Say (Diptera: Culicidae) were exposed to $40^{\circ} \mathrm{C}$ for different exposure periods (viz. half an hour, one, two and four hours) and control (room temperature, $28 \pm 6^{\circ} \mathrm{C}$ ); the percentage of egg hatching ranged from 74.14 to 96.33 $(\mathrm{F}=215.593, \mathrm{P}<0.05)$, larval mortalities were from 24.52 to $0.00 \%(\mathrm{~F}=73.287, \mathrm{P}<0.05)$, pupal mortalities ranged from 10.2 to $16.71 \%(\mathrm{~F}=34.056, \mathrm{P}<0.05)$, mean larval periods ranged from 127.9 to 155.3 hours $(\mathrm{F}=124.002, \mathrm{P}<0.05)$, mean pupal periods ranged from 30.5 to 36.1 hours $(\mathrm{F}=10.531, \mathrm{P}<0.05)$, lengths of $2^{\text {nd }}$ instar ranged from 3.82 to 4.67 $\mathrm{mm}(\mathrm{F}=16.50, \mathrm{P}<0.05)$, lengths of $3^{\text {rd }}$ instar ranged from 6.195 to $7.195 \mathrm{~mm}(\mathrm{~F}=7.558$, $\mathrm{P}<0.05)$, lengths of $4^{\text {th }}$ instar ranged from 7.395 to $8.025 \mathrm{~mm}(\mathrm{~F}=3.961, \mathrm{P}<0.05)$, mean diameter of the head capsule of $1^{\text {st }}$ instar larvae was 0.316 to $0.384 \mathrm{~mm}(\mathrm{~F}=8.308$, $\mathrm{P}<0.05)$, that of $2^{\text {nd }}$ instar larvae was 0.395 to $0.468 \mathrm{~mm}(\mathrm{~F}=4.953, \mathrm{P}<0.05)$, that of $3^{\text {rd }}$ instar larvae was 0.652 to $0.71 \mathrm{~mm}(\mathrm{~F}=2.629, \mathrm{P}>0.05)$, that of $4^{\text {th }}$ instar larvae was 0.806 to $0.91 \mathrm{~mm}(\mathrm{~F}=13.871, \mathrm{P}<0.05)$, length of the cephalothorax of pupae ranged from 1.862 to $2.062 \mathrm{~mm}(\mathrm{~F}=0.662, \mathrm{P}>0.05)$, body length of male adults ranged from 3.41 to $3.58 \mathrm{~mm}(\mathrm{~F}=0.59, \mathrm{P}>0.05)$, and that of female ranged from 3.75 to $4.09 \mathrm{~mm}(\mathrm{~F}=1.98$, $\mathrm{P}>0.05$ ), mean egg- rafts laid per female ranged from 1.4 to 2.0 and mean numbers of eggs per raft were 230 to 260 .
\end{abstract}

Keywords: High temperature, Culex quinquefasciatus, Mosquito, Immature stages

\section{Introduction}

Mosquitoes are important group of insects and one of the serious pests from the public health point of view throughout the world. Cx. quinquefasciatus breeds primarily in stagnant water with different degrees of organic contaminations. In Dhaka city $C x$. quinquefasciatus constitutes the major population of mosquitoes throughout the year (Ameen and Moizuddin 1973). The open and semi open manholes, polluted water, logged drains, ditches, marshy areas, shabby water containers, etc. are potent breeding grounds of this species of mosquito (Hamid 1979). The peak population of this species in the city is observed during the dry weather from November to December (Hamid 1979 and Begum et al. 1996). In recent years the population of this species increased significantly in Dhaka city. The species comprised nearly $60 \%$ of total mosquito population of the city in 1984 (Ameen et al. 1984), while Ahmed (1986) reported that 84\% of the mosquitoes of Dhaka city belonged to this species. 
Temperature has a profound influence upon insects in various ways. The extremes of temperature hamper their activities; control the rate of metabolism and consequently those of growth, reproduction and general behaviour. According to Wigglesworth (1965) temperature and humidity are the most important factors in the environment that influence the physiology of insect. Chapman (1969) noted that enzyme functions are efficient only within a limited range of temperature and for this reason, environmental temperature is of great importance in the lives of all insects. The higher temperature has a harmful influence on the development of insect (Davidson 1944). The optimum temperature for the insect species is generally taken to be $28^{\circ} \mathrm{C}$; any increase above this appears to be increasingly unfavourable, and over $40^{\circ} \mathrm{C}$ it is quickly fatal and insects die from the effects of heat (Mellanby 1932). The effects of temperature on various stages of mosquito were studied by Dakshinamurty and Sharma (1951), Nayar (1968), Ameen and Huda (1976), Ameen and Bhuiya (1979) and Rahman (2006).

Global warming may affect the future pattern of many arthropod-borne diseases, yet the relationship between temperature and development has been poorly described for many key vectors (Bayoh and Lindsay 2003). With this view in mind, the effects of high temperature at $40^{\circ} \mathrm{C}$ on the eggs of $C x$. quinquefasciatus exposed for different time periods and the subsequent stages developed there from after egg hatching were studied in the laboratory.

\section{Materials and Methods}

The larvae of $C x$. quinquefasciatus were collected from different breeding sources, such as stagnant water in the drainage system and various watery places in the Curzon Hall campus, University of Dhaka. The larvae were collected with the help of a sieve and were taken in a large clean plastic bowl and brought to the Entomological laboratory in the Department of Zoology, University of Dhaka. They were then washed gently in tap water for several times to clean those from impurities. The larvae were then transferred to another bowl containing clean water. Ground glucose biscuit were provided as food for the larvae, which were placed on slides within a few drops of water and were examined under a compound bi-ocular microscope (Model- C8 H30 RF200). The larvae were then identified following Service (1970).

Rearing of $C x$. quinquefasciatus: A colony was maintained in an ambient environment (temperature $28 \pm 6^{\circ} \mathrm{C}$ and $60-80 \% \mathrm{RH}$ ) of the laboratory to ensure a continuous supply of different life stages of the mosquito during the experimental period. The collected larvae were reared in a plastic bowl containing tap water and provided with finely ground biscuits (commercially known as "Energy Plus" locally) as their food. The water was changed and ground biscuits were provided daily.

The $4^{\text {th }}$ instar larvae were moulted into pupae which were separated daily from the larval bowl with the aid of a dropper and kept them in a plastic bowl that was previously filled 
with tap water. The plastic bowl with the pupae was kept in a mosquito rearing cage for the emergence of adult mosquito. After emergence, the adults were provided with $10 \%$ glucose solution daily as their food. The glucose solution was soaked in a cotton wad and placed it on a Petri dish, which was then kept inside the cage. The male mosquito only took glucose solution as food throughout their life time. For the first two or three days of emergence, the females were also fed with glucose solution.

Blood feeding is required for the nourishment and maturation of the eggs of the mosquito. From the $3^{\text {rd }}$ day after emergence, the adult female mosquitoes were allowed to feed on blood meal from a pigeon. Feathers were removed from the breast region of the pigeon and kept in a tight small iron cage which could easily be placed inside the rearing cage. The blood feeding was initiated on the $4^{\text {th }}$ day after adult emergence and continued as long as the females were alive in the cage. After taking the blood meal, the females mated with the males inside the rearing cage. A plastic bowl containing tap water was placed inside the rearing cage for the mated females to oviposit on the water surface. The number of egg rafts laid per female and the number of eggs in the rafts were counted and recorded.

Egg treatment with temperature: Only the healthy, relatively large and equal sized 6 to 18 hour-old egg-rafts were used for temperature treatment in an incubator set at $40^{\circ} \mathrm{C}$ and exposed for half an hour, one hour, two and four hours separately. The numbers of eggs per egg-raft were counted and recoded under a microscope. A thermometer was used to record the temperature of the water of Petri dish placed inside the incubator previously and when the temperature of the water was $40^{\circ} \mathrm{C}$, the egg rafts were transferred to the Petri dish water quickly. After the stipulated period of exposure. The Petri dishes were taken out of the incubator and the egg rafts were transferred as quickly as possible to another Petri dish containing distilled water and later placed inside the rearing cage at the ambient environment of the laboratory. The egg rafts were transferred on the tip of a triangular piece of blotting paper. Three replicates were used for each exposure period and a control treatment of three replicates was also taken, in which the eggs were not treated with temperature. The food were provided to the heat treated larvae and larvae in control in the same manner.

Data recorded: The data were recorded at each temperature exposure periods and control on the following aspects: hatching efficiency of the eggs; mortality of larvae and pupae; larval and pupal stage durations (stadia); body measurements, such as length of different instars of larvae, transverse diameter of the head capsule of different instars of larvae, length of cephalothoraxes of pupae, body length of male and female adults and fecundity of the female adults emerged.

Hatching efficiency of the eggs: The number of larvae hatched from the eggs was counted with the help of a magnifying glass. The eggs, which were not hatched, were regarded as killed due to heat treatment. 
Larval mortality: The mortality of all four instar larvae was recorded sequentially from the first instar larval hatching until all the $4^{\text {th }}$ instar larvae pupated. The larval mortality was counted every day. The moribund larvae were considered dead. The Abbot's formula (1925) was used when the mortality of larva in control was observed.

Pupal mortality: The mortality of pupae was recorded from the first pupation until all the adults emerged. The pupal mortality was recorded daily. The adults emerged but could not move or fly normally (deformed) were regarded as the effects of temperature and were considered dead.

Larval stage duration: This duration was recorded from the time the $1^{\text {st }}$ instar larvae first hatched to the $4^{\text {th }}$ instar larvae first pupated.

Pupal stage duration: The period between first pupation and first adult emergence was considered as the pupal stage duration.

Measurements of larval length and its head capsule: The lengths of the $2^{\text {nd }}, 3^{\text {rd }}$ and $4^{\text {th }}$ instar larvae were only recorded. As the $1^{\text {st }}$ instar larvae were very small in size, it was, therefore, difficult to measure their lengths with the instruments available in the laboratory and not attempted. In measurement, 10 larvae of each of the mentioned instars were taken into $70 \%$ ethyl alcohol and were killed. The lengths of the larvae were measured under an electronic binocular microscope by placing them on a glass slide with the help of a forceps.

Measurements of the length of pupae and their cephalothorax: The length of the cephalothorax of pupae was also measured by following the above same method.

Size of male and female adults emerged: Twenty adult mosquitoes (10 males and 10 females) were taken out from the rearing cage and were released into another empty rearing cage with the help of an aspirator. They were killed by spraying insecticideaerosol on them. The mosquitoes were then placed on a slide and their body lengths were measured in millimeters with the aid of a compound microscope.

Fecundity: The number of female mosquitoes emerged was recorded after giving them blood meal from a pigeon, and 20 engorged females were taken in a rearing cage having a Petri dish with water for oviposition by the females. When the females completed their egg laying, the total number of egg rafts laid were counted and number of eggs in each rafts were also counted under a compound microscope.

Statistical analysis: The data obtained were reported as arithmetic mean \pm standard deviation (SD). One way Analysis of Variance (ANOVA) was applied on the data to assess the treatment effect. When F-values indicated significant difference, Duncan's Multiple Range test (DMRT) was employed to discern specific difference among the treatments. All the statistical analyses were done on a computer using statistical software package SPSS. The corrected mortality was done by using Abbot's (1925) formula 
whenever necessary. The formula was $[(\mathrm{Po}-\mathrm{Pc}) /(100-\mathrm{Pc})] \times 100$, where Po $=$ percent mortality observed and $\mathrm{Pc}=$ percent mortality in control.

\section{Results and Discussion}

Hatching efficiency of the eggs: The eggs of Cx. quinquefasciatus hatched during the experiment showed significant difference $(\mathrm{F}=215.593, \mathrm{P}<0.05)$ among different exposure periods and control (Table 1). The high percentage (96.33\%) of hatching occurred in control and the lowest (74.14\%) in 4-hour exposure. A trend of gradual reduction of egg hatching was observed from control to 4-hour of exposure treatment. These results indicate that the temperature at $40^{\circ} \mathrm{C}$ with different exposures had an impact on the egg hatching of the mosquito species. Egg mortality increased gradually with increasing exposure periods at high temperature $\left(40^{\circ} \mathrm{C}\right)$ which is in conformity with the findings obtained by Ameen and Huda (1976) and Rahman (2006) in case of Aedes aegypti mosquito treated at $35^{\circ} \mathrm{C}$; and by Ameen and Bhuiya (1979) in case of Cx. pipiens fatigans treated at temperatures ranging from 32 to $44^{\circ} \mathrm{C}$. The mortality of Ae. albopictus eggs is higher in greater temperature (Alto and Juliano 2001). The eggs of $C x$. p. fatigans were not hatched at $42,40,38$ and $37^{\circ} \mathrm{C}$ on 10 minutes, 1-hour, 6-hour and 24-hour exposures, respectively (Ameen and Bhuiya 1979). Karamchandani (1935) however reported that the eggs of $C x$. p. fatigans did not hatch above $39.8^{\circ} \mathrm{C}$.

Table1. Hatching efficiency of the eggs of $C x$. quinquefasciatus treated at $40^{\circ} \mathrm{C}$ in different exposure periods and control in an ambient condition of the laboratory.

\begin{tabular}{ccccc}
\hline $\begin{array}{c}\text { Exposure } \\
\text { period } \\
(\mathrm{hrs})\end{array}$ & $\begin{array}{c}\text { Mean no. of eggs } \\
\text { per raft } \\
(\text { mean } \pm \text { SD) }\end{array}$ & $\begin{array}{c}\text { No. of larvae } \\
\text { hatched per } \\
\text { egg-raft } \\
(\text { mean } \pm \text { SD) }\end{array}$ & $\begin{array}{c}\text { No. of larvae } \\
\text { hatched per } \\
\text { egg raft } \\
(\%)\end{array}$ & F-value \\
\hline Control & $245.00 \pm 15.00$ & $236.00 \pm 15.524^{\mathrm{a}}$ & 96.33 & \\
0.5 & $230.00 \pm 24.269$ & $202.33 \pm 24.420^{\mathrm{ab}}$ & 87.97 & \\
1.0 & $255.00 \pm 22.913$ & $216.00 \pm 16.523^{\mathrm{bc}}$ & 84.71 & $215.593^{*}$ \\
2.0 & $233.66 \pm 7.767$ & $182.66 \pm 8.737^{\mathrm{c}}$ & 78.17 & \\
4.0 & $233.33 \pm 17.559$ & $173.02 \pm 16.523^{\mathrm{d}}$ & 74.14 & \\
\hline
\end{tabular}

*Significant at 5\% level; same letters in the column show significance at 5\% level in DMRT

Larval mortality: The mortality of the larvae of $C x$. quinquefasciatus is presented in Table 2. Larval mortality in control was corrected by following Abbot's formula (1925). High temperature and different exposures showed significant temperature effects $(\mathrm{F}=$ 73.287, $\mathrm{P}<0.05$ ) on larval mortalities. Karamchandini (1935). reported that the lethal temperature exposed to the $4^{\text {th }}$ instar larvae of $C x$. quinquefasciatus for one hour in subtropical regions was $37.8-38^{\circ} \mathrm{C}$. The effect of temperature on the mortality of $C x$. fatigans larvae depends on the length of exposure periods (Chapman 1969). The lethal temperature at 50 percent mortality $\left(\mathrm{LT}_{50}\right)$ of the different stages of $C x$. pepiens fatigans on 10 minutes exposure varied from 40.3 to $42.0{ }^{\circ} \mathrm{C}$; on one hour exposure the $\mathrm{LT}_{50}$ 
varied from 38.1 to $39.9{ }^{\circ} \mathrm{C}$; 6 hours exposure from 36.1 to $37.7{ }^{\circ} \mathrm{C}$ and 24 hours exposure to 34.6 to $35.8{ }^{\circ} \mathrm{C}$ (Ameen and Bhuiya 1976). Rahman ( 2006 ) reported the effects of temperature at $35^{\circ} \mathrm{C}$ on the larval and pupal

Table 2. Mortality of the larvae of $C x$. quinquefasciatus hatched from the eggs treated at $40^{\circ} \mathrm{C}$ in different exposure periods and control in an ambient condition of the laboratory.

\begin{tabular}{ccccccc}
\hline $\begin{array}{c}\text { Exposure } \\
\text { Period } \\
(\mathrm{hrs})\end{array}$ & $\begin{array}{c}\text { Total } \\
\text { number } \\
\text { of larvae } \\
\text { hatched }\end{array}$ & $\begin{array}{c}\text { Total } \\
\text { no. of } \\
\text { larvae } \\
\text { died }\end{array}$ & $\begin{array}{c}\text { Mean no. of } \\
\text { larvae died } \\
\text { (mean } \pm \text { SD) }\end{array}$ & $\begin{array}{c}\text { Mean } \\
\text { larval } \\
\text { mortality } \\
(\%)\end{array}$ & $\begin{array}{c}\text { Corrected } \\
\text { larval } \\
\text { mortality } \\
(\%)\end{array}$ & F-value \\
\hline Control & 708 & 37 & $12.33 \pm 1.527 \mathrm{a}$ & 5.23 & 0.0 & $73.287^{*}$ \\
0.5 & 607 & 117 & $39.004 .583 \mathrm{~b}$ & 19.28 & 14.83 & \\
1.0 & 648 & 136 & $45.332 .517 \mathrm{c}$ & 20.99 & 16.63 & \\
2.0 & 548 & 156 & $52.003 .606 \mathrm{~d}$ & 28.47 & 24.52 & \\
4.0 & 519 & 100 & $33.332 .082 \mathrm{e}$ & 19.27 & 14.81 & \\
\hline
\end{tabular}

*Significant at 5\% level; the same letters in the column show insignificance at 5\% level in DMRT.

mortality of Ae. aegypti up to $16 \%$ after half an hour to 24 hours of exposure of the eggs to the temperature mentioned. The mortality of the larvae and pupae of Ae aegypti, exposed to a range of 10 minutes to 24 hours, gradually increase with the rise of temperature from 33 to $46{ }^{\circ} \mathrm{C}$, the range of lethal temperature at $50 \%$ mortality was observed at $40.2-41.8{ }^{\circ} \mathrm{C}$ (Ameen and Huda 1976). They also observed that after long exposure to the above temperatures the adults failed to emerge, failed to fly normally and manifested some deformities in body parts. Adults emerged from high temperature treatments showed deformed wings (Ameen and Bhuiya 1979. Ameen and Huda 1976, and Nayar 1968).

Table 3. Mortality of the pupae of $C x$. quinquefasciatus developed from the eggs treated at $40^{\circ} \mathrm{C}$ in different exposure periods and control in an ambient condition of the laboratory.

\begin{tabular}{ccccccc}
\hline $\begin{array}{c}\text { Exposure } \\
\text { period } \\
\text { (hrs) }\end{array}$ & $\begin{array}{c}\text { Total } \\
\text { number } \\
\text { of larvae } \\
\text { pupated }\end{array}$ & $\begin{array}{c}\text { Total } \\
\text { no. of } \\
\text { adults } \\
\text { emerged }\end{array}$ & $\begin{array}{c}\text { Total } \\
\text { no. of } \\
\text { pupae } \\
\text { died }\end{array}$ & $\begin{array}{c}\text { No. of pupae } \\
\text { died } \\
(\text { mean } \pm \text { SD })\end{array}$ & $\begin{array}{c}\text { Mean } \\
\text { pupal } \\
\text { mortality } \\
(\%)\end{array}$ & F-value \\
\hline Control & 661 & 631 & 30 & $10.00 \pm 1.00^{\mathrm{a}}$ & 4.47 & \\
0.5 & 390 & 340 & 50 & $16.66 \pm 1.528^{\mathrm{b}}$ & 10.20 & $34.056^{*}$ \\
1.0 & 512 & 452 & 60 & $20.00 \pm 2.00^{\mathrm{c}}$ & 11.72 & \\
2.0 & 392 & 328 & 64 & $21.33 \pm 1.528^{\text {cd }}$ & 16.32 & \\
4.0 & 419 & 349 & 70 & $23.33 \pm 1.528^{\mathrm{d}}$ & 16.71 & \\
\hline
\end{tabular}

*Significant at 5\% level; the same letters in the column show insignificance at $5 \%$ level in DMRT.

Pupal mortality: The mortality of the pupae of Cx. quinquefasciatus is presented in Table 3. High temperature and different exposures showed significant effects $(\mathrm{F}=34.056$, $\mathrm{P}<0.05$ ) on pupal mortalities. Temperature above $40^{\circ} \mathrm{C}$ killed all the pupae of $C x$. fatigans when exposed for one hour (Karamchandini 1935). Boormann (1961) reported that the pupae of Ae. vittatus exposed for five minutes at $45.5^{\circ} \mathrm{C}$ killed $95 \%$ of pupae and exposed 
for three minutes at $48^{\circ} \mathrm{C}$ killed all the pupae exposed. Christopher (1960) obtained total mortality of the pupae of Ae. aegypti after three minutes at $48^{\circ} \mathrm{C}$ and 15 minutes at $45^{\circ} \mathrm{C}$, and $64 \%$ mortality resulted from one hour at $43^{\circ} \mathrm{C}$. Service (1970) found all pupae of $A e$. vittatus dead after 10 minutes at $46^{\circ} \mathrm{C}$ and one hour at $45^{\circ} \mathrm{C}$.

Larval and pupal stage duration: The duration of larval and pupal periods as a result of high temperature at $40^{\circ} \mathrm{C}$ for various exposure periods and control were observed significantly $(\mathrm{F}=124.002, \mathrm{P}<0.05$ in case of larvae and $\mathrm{F}=10.531, \mathrm{P}<0.05$ in case of pupae) (Table 4). The highest duration was observed in control (viz. 155.3 hours in larvae and 36.1 hours in pupae). The stage durations gradually decreased as the temperature exposure periods increased (viz. 136.8, 134.1, 131.5, and 127.9 hours larval durations respectively for $0.5,1,2$ and 4 hour exposures) and 35.2, 34.4, 32.6 and 30.5 hours pupal durations respectively for $0.5,1,2$ and 4 hour exposures. At $27^{\circ} \mathrm{C}$ the duration of the complete larval period of the mosquito, Stegomyia calopus was found 168 hours (Francis 1907). Age of pupation increased as temperature decreased from $30^{\circ} \mathrm{C}$ to $27^{\circ} \mathrm{C}$ (Lyimo et al. 1992). In the laboratory at $23^{\circ} \mathrm{C}$, the larval development time of Aedes (Ochlerotatus) albifasciatus was around 216 hours and adults emerged within one week (Luduena Almeida and Gorla 1995). The time between pupation and emergence of Stegomyia sp. at $23-27^{\circ} \mathrm{C}$ was 45 hours for males and 60 hours for females, and the mean periods of the mosquito from eclosion to pupation at $27^{\circ} \mathrm{C}$ was 154 hours and 168 hours for this period at $23-26^{\circ} \mathrm{C}$, respectively (Shannon and Putnam 1934). The larval developmental time of Ae. albopictus from egg hatching to pupation was inversely correlated with temperature, lasting 168 hours at $32^{\circ} \mathrm{C}$ and the duration of pupal period varied between 48 hours and 72 hours at that temperature (Briegel and Timmermann 2001). This indicates that with the decrease of temperature the larval and pupal period becomes lengthened. The duration of the larvae and pupae of Ae. albopictus depends also on the nature of containers in which they are developing; the total time from egg hatching to adult emergence in tree hole, bamboo stump and auto tyres in a temperature range between $18^{\circ} \mathrm{C}$ and $22^{\circ} \mathrm{C}$ was $19.6,27.3$ and 37.5 days, respectively (Gomes et al. 2001).

Table 4. Mean duration of the larvae and pupae of $C x$. quinquefasciatus obtained from the eggs treated at $40^{\circ} \mathrm{C}$ in different exposure periods and control in an ambient condition of the laboratory.

\begin{tabular}{lllllll}
\hline Stage & $\begin{array}{c}\text { Control } \\
\text { (in hrs) }\end{array}$ & \multicolumn{4}{c}{$\begin{array}{c}\text { Exposure period in hours } \\
\text { (mean } \pm \text { SD) }\end{array}$} & F-value \\
\hline & & 0.5 & 1.0 & 2.0 & 4.0 & \\
\hline Larva & $155.3 \pm 1.075^{\mathrm{a}}$ & $136.8 \pm 2.898^{\mathrm{ab}}$ & $134.1 \pm 2.767^{\mathrm{bc}}$ & $131.5 \pm 2.506^{\mathrm{c}}$ & $127.9 \pm 4.332^{\mathrm{d}}$ & $124.002^{*}$ \\
Pupa & $36.1 \pm 1.792^{\mathrm{a}}$ & $35.2 \pm 1.619^{\mathrm{ab}}$ & $34.4 \pm 2.413^{\mathrm{bc}}$ & $32.6 \pm 2.221^{\mathrm{c}}$ & $30.5 \pm 2.545^{\mathrm{d}}$ & $10.531^{*}$ \\
\hline
\end{tabular}

*Significant at $5 \%$ level; the same letters in the row show insignificance at $5 \%$ level in DMRT

Measurements of larval length and its head capsule: The lengths of $2^{\text {nd }}, 3^{\text {rd }}$, and $4^{\text {th }}$ instar larvae of Cx. quinquefasciatus at $40^{\circ} \mathrm{C}$ for various exposure periods and control are presented in Table 5 . Significant differences in length among different exposure periods and control were observed in all 
three instars [the $2^{\text {nd }}$ instar larvae $(\mathrm{F}=4.314, \mathrm{P}<0.05)$; the $3^{\text {rd }}$ instar $(\mathrm{F}=3.786, \mathrm{P}<0.05)$; and the $4^{\text {th }}$ instar $(\mathrm{F}=3.961, \mathrm{P}>0.05)$.

Table 5. Mean length of $2^{\text {nd }}, 3^{\text {rd }}$ and $4^{\text {th }}$ instar larvae of $C x$. quinquefasciatus obtained from the eggs treated at $40^{\circ} \mathrm{C}$ in different exposure periods and control in an ambient condition of the laboratory.

\begin{tabular}{lllllll}
\hline $\begin{array}{l}\text { Larval } \\
\text { instar }\end{array}$ & \multicolumn{5}{l}{ Mean larval length (in mm) in exposure period } & F-value \\
\hline & Control & $0.5 \mathrm{hr}$ & $1.0 \mathrm{hr}$ & $2.0 \mathrm{hrs}$ & $4.0 \mathrm{hrs}$ & \\
$2^{\text {nd }}$ & $4.674 \pm 0.156^{\mathrm{a}}$ & $4.11 \pm 0.256^{\mathrm{b}}$ & $4.07 \pm 0.347^{\mathrm{b}}$ & $3.93 \pm 0.25^{\mathrm{bc}}$ & $3.822 \pm 0.23^{\mathrm{c}}$ & $16.50^{*}$ \\
& & & & & & $<0.05$ \\
$3^{\text {rd }}$ & $7.195 \pm 0.254^{\mathrm{a}}$ & $6.52 \pm 0.476^{\mathrm{b}}$ & $6.527 \pm 0.401^{\mathrm{b}}$ & $6.485 \pm 0.477^{\mathrm{b}}$ & $6.195 \pm 0.466^{\mathrm{b}}$ & $7.558^{*}<0.05$ \\
$4^{\text {th }}$ & $8.025 \pm 0.437^{\mathrm{a}}$ & $7.905 \pm 0.265^{\mathrm{a}}$ & $7.79 \pm 0.39^{\mathrm{a}}$ & $7.675 \pm 0.408^{\mathrm{ab}}$ & $7.395 \pm 0.393^{\mathrm{b}}$ & $3.961^{*}<0.05$ \\
\hline
\end{tabular}

*Significant at 5\% level; the same letters in the row show insignificance at 5\% level in DMRT.

The transverse diameters of the head capsules of $1^{\text {st }}, 2^{\text {nd }}$ and $4^{\text {th }}$ instar larvae were observed significant $(\mathrm{F}=8.308, \mathrm{P}<0.05 ; \mathrm{F}=4.953, \mathrm{P}<0.05$ and $\mathrm{F}=13.871, \mathrm{P}<0.05$; respectively), but of $3^{\text {rd }}$ instar larvae showed insignificance $(\mathrm{F}=2.629, \mathrm{P}<0.05)$ (Table 6).

Temperatures ranging from $15^{\circ} \mathrm{C}$ to $31^{\circ} \mathrm{C}$ significantly affect the size of head capsule widths of the larval instars of Ae. albopictus and Ae. triseriatus (Say) in laboratory (Teng and Apperson 1996), which is in conformity with the present results at higher temperature.

Table 6. Mean diameter of the head capsule of all four larval instars of Cx. quinquefasciatus obtained from the eggs treated at $40^{\circ} \mathrm{C}$ in different exposure periods and control in an ambient condition of the laboratory.

\begin{tabular}{lllllll}
\hline Larval & \multicolumn{5}{l}{ Mean larval length (in mm) in exposure period } & F-value P \\
\hline & Control & $0.5 \mathrm{hr}$ & $1 \mathrm{hr}$ & $2 \mathrm{hrs}$ & $4 \mathrm{hrs}$ & \\
$* 1^{\text {st }}$ & $0.384 \pm 0.025^{\mathrm{a}}$ & $0.371 \pm 0.026^{\mathrm{ab}}$ & $0.352 \pm 0.037^{\mathrm{b}}$ & $0.346 \pm 0.027^{\mathrm{b}}$ & $0.316 \pm 0.026^{\mathrm{c}}$ & $8.308^{*}<0.05$ \\
$* 2^{\text {nd }}$ & $0.468 \pm 0.038^{\mathrm{a}}$ & $0.449 \pm 0.047^{\mathrm{a}}$ & $0.445 \pm 0.042^{\mathrm{a}}$ & $0.432 \pm 0.033^{\mathrm{a}}$ & $0.395 \pm 0.03^{\mathrm{b}}$ & $4.953^{*}<0.05$ \\
$3^{\text {rd }}$ & $0.910 \pm 0.044$ & $0.704 \pm 0.047$ & $0.692 \pm 0.05$ & $0.675 \pm 0.043$ & $0.652 \pm 0.045$ & $2.629>0.05$ \\
$*^{\text {th }}$ & $0.910 \pm 0.034^{\mathrm{a}}$ & $0.882 \pm 0.031^{\mathrm{ab}}$ & $0.872 \pm 0.035^{\mathrm{b}}$ & $0.855 \pm 0.032^{\mathrm{b}}$ & $0.806 \pm 0.032^{\mathrm{c}}$ & $13.871 *<0.05$ \\
\hline
\end{tabular}

*Significant at 5\% level; the same letters in the row show insignificance at 5\% level in DMRT.

Measurements of pupal length and its cephalothorax: Size of male and female adults emerged-- The results presented in Table 7 show that the length of the cephalothorax of the pupae of $C x$. quinquefasciatus developed from the eggs treated with high temperature and different exposure periods showing insignificance at $5 \%$ level $(\mathrm{F}=0.662, \mathrm{P}>0.05)$.

From the Table 7 it is evident that temperature showed no effect $(\mathrm{F}=0.59, \mathrm{P}<0.05$ for males and $\mathrm{F}=1.98, \mathrm{P}<0.05$ for females) on the body length of adult male and females $C x$. quinquefasciatus emerged from the eggs treated with high temperature at $40^{\circ} \mathrm{C}$. Adult size increased as temperature decreased. Alto and Juliano (2001) reported that temperature affects the size of the adults of Ae. albopictus; size of the adults decreased with increased temperature. In the present findings, high 
temperature tended to lower the body size of the adult mosquito, but not significantly different in size in different exposure periods.

Table 7. Mean cephalothoracic length of pupae and adult body length of Cx. quinquefasciatus obtained from the eggs treated at $40^{\circ} \mathrm{C}$ in different exposure periods and control in an ambient condition of the laboratory.

\begin{tabular}{|c|c|c|c|c|c|c|}
\hline \multirow{3}{*}{$\begin{array}{l}\text { Pupa } \\
\text { and Adult } \\
\text { Cephalo- } \\
\text { thorax } \\
\text { length }\end{array}$} & \multicolumn{5}{|c|}{ Mean larval length (in $\mathrm{mm}$ ) in exposure period } & \multirow{3}{*}{$\begin{array}{l}\text { F-value } P \\
0.662>0.05\end{array}$} \\
\hline & Control & $0.5 \mathrm{hr}$ & $1 \mathrm{hr}$ & $2 \mathrm{hrs}$ & $4 \mathrm{hrs}$ & \\
\hline & $2.062 \pm 0.38$ & $1.933 \pm 0.288$ & $1.898 \pm 0.304$ & $1.862 \pm 0.281$ & $1.89 \pm 0.26$ & \\
\hline $\begin{array}{l}\text { Male } \\
\text { body } \\
\text { length }\end{array}$ & $3.58 \pm 0.27$ & $3.44 \pm 0.299$ & $3.41 \pm 0.296$ & $3.42 \pm 0.308$ & $3.49 \pm 0.26$ & $0.59>0.05$ \\
\hline $\begin{array}{l}\text { Female } \\
\text { body } \\
\text { length }\end{array}$ & $4.09 \pm 0.269$ & $3.96 \pm 0.317$ & $3.93 \pm 0.267$ & $3.89 \pm 0.285$ & $3.75 \pm 0.237$ & $1.98>0.05$ \\
\hline
\end{tabular}

The Table 8 shows that the females laid the highest number of eggs in control (260 per female) and lowest at 4-hour exposure ( 230 per female). The fecundity of the mosquito deceased gradually, viz 252, 245, 237 and 230 eggs laid per female in half an hour, one, two and four hours of exposure, respectively with the increase of exposure periods. Temperature affects the production of Ae. albopictus; greater temperature results in greater production of the adults in mosquito (Alto and Juliano 2001). The fecundity of Ae. cantans (Meig.) decreased with the decrease in adult female size and also a reduction in numbers of eggs in successive ovipositions (Service 1977).

Table 8. Fecundity of the female $C x$. quinquefasciatus obtained from the eggs treated at $40^{\circ} \mathrm{C}$ in different exposure periods and control in an ambient condition of the laboratory.

\begin{tabular}{cccc}
\hline $\begin{array}{c}\text { Exposure } \\
\text { period } \\
\text { (in hrs) }\end{array}$ & $\begin{array}{c}\text { Total number of } \\
\text { egg-rafts laid by } \\
\text { ten females }\end{array}$ & $\begin{array}{c}\text { Mean number of } \\
\text { egg-rafts laid per } \\
\text { female }\end{array}$ & $\begin{array}{c}\text { Mean number of } \\
\text { eggs per raft }\end{array}$ \\
\hline Control & 20 & 2.0 & 260 \\
0.5 & 18 & 1.8 & 252 \\
1.0 & 17 & 1.7 & 245 \\
2.0 & 16 & 1.6 & 237 \\
4.0 & 14 & 1.4 & 230 \\
\hline
\end{tabular}

From the study it may be concluded that the eggs treated with high temperature at $40^{\circ} \mathrm{C}$ were significantly affected and the larvae hatched there-from and moulted up to the $4^{\text {th }}$ instar were also affected variously; pupal and adults were apparently little affected due to the high temperature and exposures. Further work may be initiated to look into this aspect in detail as to whether high temperature (=simulating global warming) has a discernable effects on mosquito life in nature, which may be useful in formulating control strategy of arthropod-borne disease vectors, particularly mosquito species. 


\section{References}

Abbot, W.S. 1925. A method of computing the effectiveness of an insecticide. J. econ.Entomol. 18: 265-267.

Ahmed, T.U. 1986. Mosquito problem in Bangladesh with special emphasis on urban mosquito situation and its control. Abstracts in Souvenir, the 3rd Biennial Conference of Bangladesh Entomological Society, pp.10-27.

Alto, B.W. and S.A. Juliano. 2001. Temperature effects on the Dynamics of Aedes albopictus (Diptera: Culicidae) populations in the laboratory. Med. Entomol. Zool. 38(4): 548-556.

Ameen, M. and M. Moizuddin. 1973. Bionomics of the common mosquioes of Dacca. J. nat. Hist. 7: $1-21$

Ameen, M. and B.A. Bhuiya. 1979. Effects of high temperatures on the immature stages of Culex pipiens fatigans (Wiedemann) (Diptera: Culicidae). Dacca Univ. Stud., B. XXVII (2):169-180.

Ameen, M. and K.M.N. Huda. 1976. Effect of high temperatures on the larvae and pupae of Aedes aegypti (L.) (Diptera:Culicidae), Bangladesh J. Zool. 4(2):73-84.

Ameen M, Hossain and M.D.H. Khan.1984. Resting behaviour, biting activity pattern and host preference of the common mosquitoes of Dhaka city. Bangladesh J. Zool. 10(1): 35-48.

Bayoh , M.N. and S.W. Lindsay. 2003. Effect of temperature on the development of the aquatic stages of Anopheles gambiae sensu stricto (Diptera: Culicidae). Bull. Entomol Res. 93: 375-381.

Begum, A., M.A. Hamid and M.Elias.1996. The ecology and seasonal fluctuations of mosquito larvae in a lake of Dhaka city. Bangladesh J. Zool. 14(1): 14-18.

Boormann, J.P.T. 1961. Observations on the habits of mosquitoes of Plateau Province, Northern Nigeria, with particular reference to Aedes (Stegomyia) vittatus (Bigot). Bull. ent. Res. 52: 709-725.

Briegel, H. and S.E. Timmermann 2001. Aedes albopictus (Diptera: Culicidae): Physiological Aspects of Development and Reproduction. J. Med. Entomol. pp 566-571.

Chapman, R.F. 1969. Insects: strucrture and functions. The English University Press Ltd. Prescott and London, xii $+819 \mathrm{pp}$.

Christopher, S.R. 1960. Aedes aegypti (L.), the yellow fever mosquito: its life history, bionomics and structure. Cambridge Univ. Press, London, xii $+739 \mathrm{pp}$.

Dakshinamurty, S. and M.I.D. Sharma. 1951. The temperature preferences of mosquitoes. Indian J. Malariol. Calcutta. 5: 221-227.

Davidson, J. 1944. On the relationship between temperature and rate of development of insect at constant temperatures. J. Anim. Ecol. 13:29-38.

Francis, E. 1907. Obsevations on the life cycle of Stegomyia calopus Pub. Hlth Rep. Was 22: 381-383.

Gomes, A.C., S.L.D. Gotlieb, C.C.A. Marques, M.B. Paula and G.R.A.M. Marques. 2001. Duration of larval and pupal development stages of Aedes albopictus in natural and artificial containers. Rev. Saude. Publca. 29(1): (downloaded from the internate).

Hagstrum, D.W. and E.B. Workman. 1971. Interaction of temperature and feeding rate in determining the rate of development of larval Culex tarsalis (Diptera: Culicidae) Ann. Ent. Soc. Am. 64(3): 668-671.

Hamid, M.A.1979. Studies on the ecology and seasonal fluctuation of Culex quinquefasiatus larvae in Dhaka City. M.Sc. thesis, Department of Zoology, University of Dahaka, 126 pp.

Karamchandini, P.V. 1935. The effect of heat and atmospheric humidity on all stages of Culex fatigans. Rec. Malar. Surv. India. 5:23-28. 
Luduena Almeida, F.F. and D.E. Gorla. 1995. The biology of Aedes (Ochlerotatus) albifasciatus Macquart, 1838 (Diptera: Culicidae) in Central Argentina . Mem. Inst. Cruz. Rio de Janeirol. 90(4): 463-468.

Lyimo, E.O., W. Takken and J.C. Koella. 1992. Effect of rearing temperature and larval density on larval survival, age at pupation, and adult size of Anopheles gambiae Entomol. Expt. Appl. 63(3): 265-271.

Mellanby, K. 1932. The influence of atmospheric humidity on the thermal death point of a number of insects. J. Exp. Biol. 9:22-31.

Nayar, J.K. 1968. Effects of larval and pupal environmental factors on biological status of adults at emergence in Aedes tritaeniorhynchus (Weid.) Bull. Ent. Res. 58(4): 811-827.

Rahman. F.2006. Effects of high temperature on the eggs of Aedes aegypti L. (Diptera: Culicidae) and the subsequent stages developed there from. M.Sc. thesis, Department of Zoology, University of Dhaka, 65p.

Service, M.W. 1970. Studies on the biology and taxonomy of Aedes (Stegomyia) vittatus (Biot) (Diptera: Culicidae) in Northern Nigeria. Trans Roy. Ent. Soc. London. 122: 101-143.

Service, M.W. 1977. Ecological and Biological studies on Aedes cantans (Meig.) (Diptera: Culicidae) in Southern England. J. App. Ecol. 14(1): 159-196

Shannon, R.C. and P. Putnam. 1934. The biology of Stegomyia under laboratory conditions. I. The analysis of factors which influence larval development. Proc. Ent. Soc. Wash. 36: 85216.

Teng, H.J. and C.S. Apperson. 1996. Identification of larval instar of Aedes albopictus (Skuse) and Aedes triseriatus (Say) (Diptera: Culicidae) based on head capsule size. J. Vector Ecol. 21: 186-191.

Wigglesworth, V.B. 1965. The principles of Insect Physiology. (6 $6^{\text {th }}$ Ed., revised), Methuen and Co Ltd., London viii 741 pp.

(Received revised manuscript on 3 June 2013) 